\title{
ЕНЕРГЕТИЧНА ХАРАКТЕРИСТИКА РЕЖИМІВ СУШІННЯ БУКОВИХ ПИЛОМАТЕРІАЛІВ
}

Розглянуто актуальний науково-прикладний аспект аналізу режимів за тепловим потенціалом сушильного середовища тепловмістом вологого повітря. Наведено розрахункові формули для визначення тепловмісту і вологовмісту повітря, як агента сушіння. Обрано для дослідження низькотемпературні режими сушіння букових пиломатеріалів: за редакцією профеcopa I. В. Кречетова, професора П. В. Соколова та європейської фірми Brunner-Hildebrand. Проаналізовано режими сушіння за величиною зміни ентальпії повітря для різних ступенів режимів сушіння та різних товщин букових пиломатеріалів (товщина від $S_{1}=19$ мм до $S_{1}=70$ мм). Наведено в підсумку таблиць інтегральне значення ентальпії для обраних режимів і товщин пиломатеріалів. Застосовано для апроксимації зміни ентальпії повітря залежно від вологості деревини рівняння параболи третього порядку. Наведено інтегральний вигляд формули зміни ентальпії повітря залежно від вологості деревини. Апроксимаційні залежності мають адекватне наближення до розрахункових, що видно з наведених у роботі графіків. Визначено, що для всіх наведених у роботі режимів сушіння інтегральне значення ентальпії зменшується із збільшенням товщини пиломатеріалів, що підтверджує той факт, що для сушіння більших товщин пиломатеріалів тепловий потенціал має бути нижчим, через менші витрати теплоти на процес сушіння. Визначено, що найбільших витрат теплової енергії потребує період зміни вологості від $W=40 \%$ до $W=20 \%$ через найбільший градієнт вологості по товщині матеріалу. Доведено, що відповідно до витрат теплової енергії на процес сушіння потрібно регулювати роботу агрегатів теплової енергії.

Ключові слова: режим сушіння; пиломатеріали; вологість деревини; тепловміст і вологовміст сушильного середовища; інтегральне значення ентальпія; апроксимація.

Вступ. Конвективне сушіння деревини є складним масообмінним процесом, який має зовнішню і внутрішню складові частини. До зовнішньої складової частини віднесено теплообмін сушильного середовища 3 поверхнею матеріалу та вологообмін поверхні матеріалу із середовищем. До внутрішньої складової частини віднесено передачу тепла всередині матеріалу, яке може здійснюватись шляхом теплопровідності, тепловим випромінюванням стінок клітин та конвекцією всередині макрокапілярів та внутрішнє перенесення вологи за рахунок, в основному, молекулярної дифузії (Bilei, 2005; Bilei, et al., 2013).

Переміщення вологи із внутрішніх до зовнішніх шарів деревини потребує великих витрат теплової енергії i, по-перше, на енергію відриву молекул води з елементів внутрішньої будови деревини, а по-друге, на переміщення вологи до поверхневих шарів за рахунок потенціалів вологопровідності шляхом молекулярної дифузії (Bilei \& Pavliust, 2008; Ozarkov, Soroka \& Gryciuk, 1997).

Необхідна кількість тепла до поверхні матеріалу передається шляхом конвективного теплообміну сушильного середовища 3 поверхнею матеріалу. Тепловою характеристикою сушильного середовища, зазвичай вологого повітря, є його тепловміст або ентальпія, яка характеризує кількість теплоти, яку має 1 кг вологого повітря за сумарним тепловмістом сухого повітря та водя- ної пари (Bilei \& Pavliust, 2008).

Викладення основного матеріалу. Для аналізу режимів сушіння за тепловим потенціалом (тепловмістом) повітря використано відомі діючі режими сушіння за редакцією різних авторів. Якщо в загальному вигляді представити залежність тепловмісту (ентальпії) від вологості деревини і товщини матеріалу, то отримаємо різні функціональні залежності $H=f\left(W, S_{1}\right)$, які, наприклад, для режимів за редакцією І. В. Кречетова зображено на рис. 1. Найпридатнішою залежністю для опису зміни ентальпії в процесі сушіння є рівняння параболи третього порядку виду

$$
F(W)=a_{0}+a_{1} W+a_{2} W^{2}+a_{3} W^{3} .
$$

Якщо проінтегрувати цю функцію в діапазоні вологості від $W_{0}$ до $W_{\kappa}$, то отримаємо площу, яка виражає залежність

$$
H_{\Sigma}=\int_{W_{\kappa}}^{W_{0}}\left(a_{0}+a_{1} W+a_{2} W^{2}+a_{3} W^{3}\right) d W, \frac{\text { кДж }}{\text { кг повітря }} .
$$

Методика аналізу режимів сушіння букових пиломатеріалів полягає у тому, що для кожного ступеня режиму (за режимними параметрами), кожної товщини пиломатеріалів в діапазоні $S_{1}=19 \ldots 70$ мм та для кожної обраної для аналізу редакції режимів визначено похідні параметри (тиск насичення $\left(P_{H}\right.$, Па); вологовміст $(d$, г/кг); приведений об'єм $\left(V, \mathrm{~m}^{3} / \kappa г\right)$; тривалість сушіння $\left(\tau_{p}\right.$, год); кількість випаровуваної вологи $\left(M_{c}\right.$, кг/с); ен-

\section{Інформація про авторів:}

Соколовський Ігор Андрійович, канд. техн. наук, доцент, кафедра технологій захисту навколишнього середовища і деревини, безпеки життєдіяльності та соціальних комунікацій. Email: igorsokolov@ukr.net

Цитування за ДСту: Соколовський І. А. Енергетична характеристика режимів сушіння букових пиломатеріалів. Науковий вісник НЛтУ України. 2019, т. 29, № 1. С. 106-109.

Citation APA: Sokolovskyi, I. A. (2019). Energy Characteristics of Drying Modes of Beech Lumber. Scientific Bulletin of UNFU, 29(1), 106109. https://doi.org/10.15421/40290123 
тальпія повітря (H, кДж/кг повітря)) та загальне (інтегральне) значення ентальпії $\left(H_{\Sigma}\right)$ для даної товщини матеріалу.

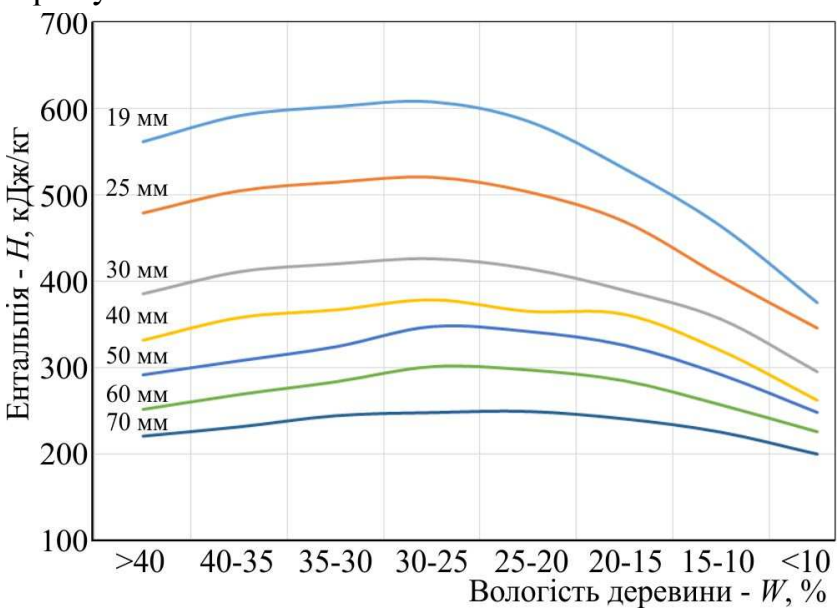

Рис. 1. Залежність $H=f\left(W, S_{1}\right)$ для режимів за редакцією I. В. Кречетова (Krechetov, 1972)

Складено табл. 1, в якій представлено зміну ентальпії повітря в режимах за редакцією I. В. Кречетова (Krechetov, 1987) залежно від товщини та ступеня режиму, а також інтегральне значення ентальпії для кожної товщини пиломатеріалів. Згідно 3 даними табл. 1, зміна ентальпії в процесі сушіння відбувається за певною закономірністю (рис. 2).

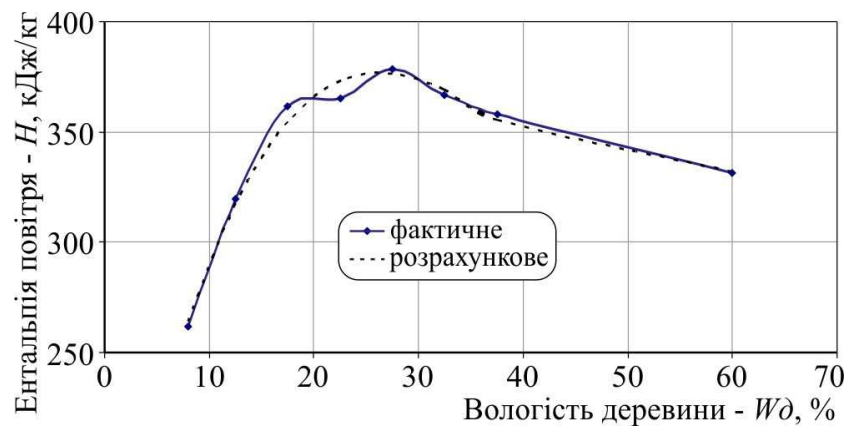

Рис. 2. Зміна ентальпії в процесі сушіння букових пиломатеріалів товщиною $S_{1}=40$ мм (I. В. Кречетов)

Там же представлено ідентифікацію розрахункових залежностей і графіків, побудованих за табличними даними для всіх товщин пиломатеріалів. Для прикладу вивчення характеру зміни ентальпії в процесі сушіння візьмемо товщину букових пиломатеріалів $S_{1}=40$ мм (див. рис. 2). Отже, з табл. 1 виділяємо відповідні дані, визначаємо середню вологість деревини ( $\left.\bar{W}_{\partial}\right)$ для різних ступенів, які наведено в табл. 2 разом з розрахунковими даними, обчисленими за залежністю (3).

Табл. 1. Зміна ентальпії повітря (режими за редакцісю I. В. Кречетова (Krechetov, 1987)

\begin{tabular}{|c|c|c|c|c|c|c|c|c|}
\hline \multirow{3}{*}{$\begin{array}{l}\text { Ступінь } \\
\text { режиму }\end{array}$} & \multirow{3}{*}{ Зміна вологості, $\Delta W, \%$} & \multicolumn{7}{|c|}{ Товщина матеріалу $-S_{1}$, мм } \\
\hline & & 19 & 25 & 30 & 40 & 50 & 60 & 70 \\
\hline & & \multicolumn{7}{|c|}{ Ентальпія повітря - } \\
\hline I & $>40$ & 561,4 & 479,1 & 385,4 & 331,6 & 292,1 & 251,9 & 221,7 \\
\hline II & $40-35$ & 591,3 & 504,7 & 411,0 & 357,9 & 308,4 & 269,1 & 232,4 \\
\hline III & $35-30$ & 601,8 & 514,6 & 420,1 & 366,8 & 324,6 & 283,7 & 245,3 \\
\hline IV & $30-25$ & 607,3 & 520,4 & 426,1 & 378,5 & 348,1 & 301,2 & 248,9 \\
\hline $\mathrm{V}$ & $25-20$ & 584,9 & 503,5 & 414,6 & 365,2 & 342,4 & 297,4 & 250,2 \\
\hline VI & $20-15$ & 530,2 & 469,1 & 389,3 & 361,6 & 326,3 & 284,8 & 241,6 \\
\hline VII & $15-10$ & 464,0 & 406,0 & 356,0 & 319,6 & 292,4 & 257,1 & 226,3 \\
\hline VIII & $<10$ & 375,8 & 346,4 & 295,0 & 262,0 & 248,4 & 226,1 & 200,9 \\
\hline \multicolumn{2}{|c|}{$\begin{array}{c}\text { Інтегральне значення ентальпії }-H_{\Sigma} \cdot 10^{3} \text {, } \\
\text { кДж/кг повітря }\end{array}$} & 28,95 & 24,93 & 20,42 & 17,83 & 15,85 & 13,87 & 12,00 \\
\hline
\end{tabular}

Табл. 2. Розрахунок зміни ентальпії для $S_{1}=40$ мм

\begin{tabular}{|c|c|c|c|c|c|c|c|}
\hline \multirow{2}{*}{$\bar{W}_{\partial}, \%$} & \multicolumn{2}{|c}{ Н, кДж/кг } & \multicolumn{2}{|c|}{ Відхилення } & & \\
\cline { 2 - 6 } & факт. & розр. & абсолютне & відносне & & $a_{0}=$ & 112,5043 \\
\hline 60 & 331,57 & 331,76 & 0,19 & $-0,06$ & & $a_{1}=$ & 24,0909 \\
\hline 37,5 & 357,88 & 355,42 & 2,46 & 0,69 & & $a_{2}=$ & $-0,6848$ \\
\hline 32,5 & 366,83 & 369,06 & 2,23 & $-0,61$ & & $a_{3}=$ & 0,0057 \\
\hline 27,5 & 378,47 & 376,43 & 2,04 & 0,54 & & $S^{2}=$ & 130,744 \\
\hline 22,5 & 365,16 & 373,21 & 8,05 & $-2,20$ & & & \multicolumn{2}{|c|}{ Ентальпія (інтеграл) } \\
\hline 17,5 & 361,62 & 355,12 & 6,50 & 1,80 & & \multirow{2}{*}{17834,61} & кДж \\
\hline 12,5 & 319,57 & 317,85 & 1,73 & 0,54 & & & кг повітря \\
\hline 8 & 262,00 & 264,34 & 2,34 & $-0,89$ & & & \\
\hline
\end{tabular}

Зміна ентальпії для всіх товщин описується параболічною залежністю для кожної товщини та вологості матеріалу і гіперболічною залежністю від товщини матеріалу для кожного ступеня режиму. Інтегральне значення ентальпії також змінюється за параболічною залежністю від вологості матеріалу $\left(\bar{W}_{\partial}\right)$

$$
H=112,5043+24,0909 \cdot W_{\partial}-0,6848 \cdot W_{\partial}^{2}+0,0057 \cdot W_{\partial}^{3} .
$$

У табл. 3 представлено зміну ентальпії повітря в режимах за редакцією П. В. Соколова (Sokolov, 1968) залежно від товщини матеріалу та ступеня режиму, а також інтегральне значення ентальпії для кожного діапазону товщини пиломатеріалів. Згідно з даними табл. 3, зміна ентальпії повітря відбувається за аналогічними залежностями. Варто тільки зазначити, що сума середніх квадратичних відхилень між розрахунковими і табличними даними для режимів за редакцією П. В. Соколова $є$ майже на порядок більшою, ніж за редакцією I. В. Кречетова, що підтверджує висновок про їх апріорне походження. Для прикладу, в табл. 4 наведено результати розрахунку зміни ентальпії в процесі сушіння пиломатеріалів товщиною $\mathrm{S}_{1}=40$ мм. Розрахункова залежність має вигляд

$$
H=199,4060+15,6430 \cdot W_{\partial}-0,3301 \cdot W_{\partial}^{2}+0,0019 \cdot W_{\partial}^{3} \cdot(4)
$$

Характер зміни ентальпії зображено на рис. 3. 
Табл. 3. Зміна ентальпії повітря (режими за редакцією П. В. Соколова (Sokolov, 1968)

\begin{tabular}{|c|c|c|c|c|c|c|c|}
\hline \multirow{3}{*}{$\begin{array}{l}\text { Ступінь } \\
\text { режиму }\end{array}$} & \multirow{3}{*}{ Зміна вологості, $\Delta W, \%$} & \multicolumn{6}{|c|}{ Товщина матеріалу $-S_{1}$, мм } \\
\hline & & $19-22$ & $25-30$ & $31-40$ & $41-50$ & $51-60$ & $61-70$ \\
\hline & & \multicolumn{6}{|c|}{ Ентальпія повітря - H, кДж/кг } \\
\hline $\mathrm{I}$ & $>40$ & 539,1 & 455,1 & 367,2 & 320,3 & 276,4 & 244,0 \\
\hline II & $40-30$ & 620,6 & 522,1 & 431,7 & 366,8 & 320,6 & 283,7 \\
\hline III & $30-20$ & 556,1 & 471,1 & 401,6 & 343,0 & 302,7 & 263,5 \\
\hline IV & $20-15$ & 530,2 & 469,1 & 382,1 & 333,4 & 304,8 & 266,8 \\
\hline $\mathrm{V}$ & $15-10$ & 475,4 & 396,5 & 364 & 326,3 & 275,4 & 242,7 \\
\hline VI & $<10$ & 375,8 & 356,5 & 295,0 & 262,0 & 248,4 & 226,1 \\
\hline \multicolumn{2}{|c|}{$\begin{array}{c}\text { Інтегральне значення ентальпії }-H_{\Sigma} \cdot 10^{3}, \text { кДж/кг } \\
\text { повітря }\end{array}$} & 29,15 & 24,89 & 20,58 & 17,65 & 16,57 & 13,80 \\
\hline
\end{tabular}

Табл. 4. Розрахунок зміни ентальпії для $S_{1}=40$ мм

\begin{tabular}{|c|c|c|c|c|c|c|}
\hline \multirow{2}{*}{$\bar{W}_{\partial}, \%$} & \multicolumn{2}{|c|}{ Н, кДж/кг } & \multicolumn{2}{|c|}{ Відхилення } & \multirow[b]{2}{*}{$a_{0}=$} & \multirow[b]{2}{*}{199,4060} \\
\hline & факт. & розр. & абсолютне & відносне & & \\
\hline 60 & 367,16 & 367,58 & 0,41 & $-0,11$ & $a_{1}=$ & 15,6430 \\
\hline 35 & 431,65 & 425,51 & 6,14 & 1,42 & $a_{2}=$ & $-0,3301$ \\
\hline 25 & 401,63 & 414,41 & 12,78 & $-3,18$ & $a_{3}=$ & 0,0019 \\
\hline 17,5 & 382,06 & 382,44 & 0,38 & $-0,10$ & $S^{2}=$ & 573,629 \\
\hline 12,5 & 364,01 & 347,15 & 16,86 & 4,63 & & \\
\hline 8 & 295,02 & 304,42 & 9,39 & $-3,18$ & \multicolumn{2}{|c|}{ Ентальпія (інтеграл) } \\
\hline & & & & & \multirow{2}{*}{20582,82} & кДж \\
\hline & & & & & & кГ повітря \\
\hline
\end{tabular}

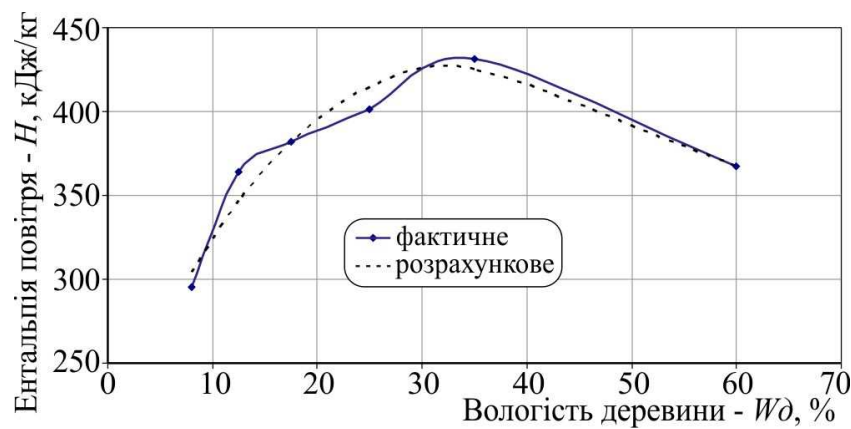

Рис. 3. Зміна ентальпії в процесі сушіння букових пиломатеріалів товщиною $S_{1}=40$ мм (П. В. Соколов)

Складено табл. 5, в якій представлено зміну ентальпії повітря в режимах за даними фірми Brunner-Hildebrand (Auflage, 1987) залежно від товщини матеріалу та ступеня режиму, а також інтегральне значення для кожного діапазону товщини пиломатеріалів.

Згідно з даними табл. 5, характер зміни ентальпії залежно від товщини описується гіперболічною, а від вологості - параболічною залежністю, що $є$ аналогічним режимам за редакцією І. В. Кречетова та П. В. Соколова. Тут також для прикладу покажемо зміну ентальпії в процесі сушіння букових пиломатеріалів товщиною $S_{1}=40$ мм. У табл. 6 наведено розрахункові дані, а на рис. 4 показано характер зміни ентальпії. Розрахункова залежність має вигляд

$H=101,8844+13,1519 \cdot W_{\partial}-0,2594 \cdot W_{\partial}^{2}+0,0015 \cdot W_{\partial}{ }^{3}$.
Табл. 5. Зміна ентальпії повітря

(режими Brunner-Hildebrand (Auflage, 1987))

\begin{tabular}{|c|c|c|c|c|}
\hline \multirow{3}{*}{\begin{tabular}{|c} 
Сту- \\
пінь \\
режи- \\
му \\
\end{tabular}} & \multirow{3}{*}{$\begin{array}{c}\text { Зміна вологості, } \\
\Delta W, \%\end{array}$} & \multicolumn{3}{|c|}{ Товщина матеріалу $-S_{1}$, мм } \\
\hline & & $<30$ & $31-60$ & $>61$ \\
\hline & & \multicolumn{3}{|c|}{ Ентальпія повітря - $H$, кДж/кг } \\
\hline I & $>70$ & 335,4 & 275,0 & 272,1 \\
\hline II & $70-60$ & 362,2 & 282,7 & 285,8 \\
\hline III & $60-50$ & 376,3 & 294,0 & 296,9 \\
\hline IV & $50-40$ & 386,0 & 304,9 & 308,4 \\
\hline V & $40-30$ & 381,2 & 312,8 & 304,9 \\
\hline VI & $30-25$ & 345,8 & 305,0 & 297,3 \\
\hline VII & $25-20$ & 316,9 & 284,8 & 280,8 \\
\hline VII & $20-15$ & 299,8 & 253,4 & 246,3 \\
\hline IX & $15-10$ & 273,5 & 226,2 & 209,8 \\
\hline $\mathrm{X}$ & $<10$ & 249,1 & 195,1 & 188,3 \\
\hline \multicolumn{2}{|c|}{$\begin{array}{c}\text { Інтегральне значення ен- } \\
\text { тальпії }-H_{\Sigma} \cdot 10^{3}, \text { кДж/кг } \\
\text { повітря }\end{array}$} & 22,72 & 18,52 & 18,36 \\
\hline
\end{tabular}

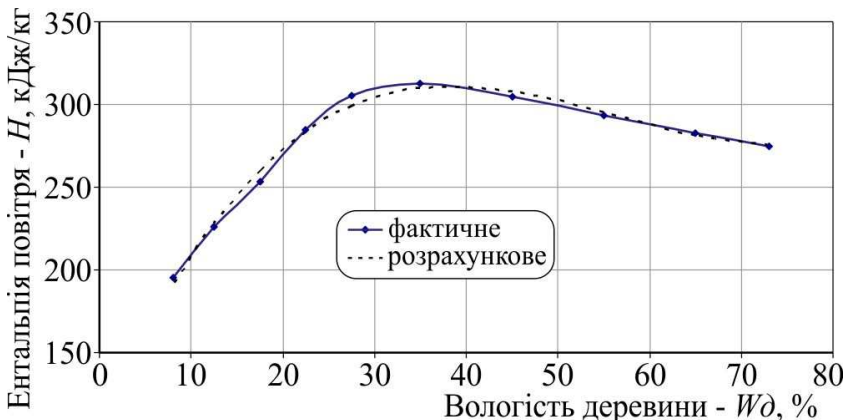

Рис. 4. Зміна ентальпії в процесі сушіння букових пиломатеріалів товщиною $\mathrm{S}_{1}=40$ мм (Brunner-Hildebrand)

Табл. 6. Розрахунок зміни ентальпії для $S_{1}=40$ мм

\begin{tabular}{|c|c|c|c|c|c|c|}
\hline \multirow{2}{*}{$\bar{W}_{\partial}, \%$} & \multicolumn{2}{|c|}{$H$, кДж/кг } & \multicolumn{2}{|c|}{ Відхилення } & & \\
\hline & факт & розр & абсолютне & відносне & $a_{0}=$ & 101,8844 \\
\hline 73 & 275,00 & 275,13 & 0,13 & $-0,05$ & $a_{1}=$ & 13,1519 \\
\hline 65 & 282,65 & 281,19 & 1,46 & 0,52 & $a_{2}=$ & $-0,2594$ \\
\hline 55 & 293,59 & 295,25 & 1,66 & $-0,57$ & $a_{3}=$ & 0,0015 \\
\hline 45 & 304,87 & 307,94 & 3,07 & $-1,01$ & $S^{2}=$ & 131,4302 \\
\hline 35 & 312,79 & 310,08 & 2,71 & 0,87 & & \\
\hline 28 & 305,04 & 299,23 & 5,81 & 1,90 & \multicolumn{2}{|c|}{ Ентальпія (інтеграл) } \\
\hline 23 & 284,81 & 283,92 & 0,89 & 0,31 & \multirow{2}{*}{18518,88} & кДж \\
\hline 18 & 253,43 & 260,81 & 7,38 & $-2,91$ & & кг повітря \\
\hline 13 & 226,19 & 228,74 & 2,55 & $-1,13$ & & \\
\hline 8 & 195,06 & 191,28 & 3,77 & 1,93 & & \\
\hline
\end{tabular}

Отже, всі три типи режимів за середнім значенням ентальпії мало відрізняються.
Користуючись попередньою методикою, знайдемо залежність ентальпії від товщини матеріалу $\left(S_{1}\right)$ та во- 
логості деревини $(W)$, яка для даних режимів буде мати вигляд

$$
H_{i}=\frac{2880,75+23,75 \cdot W_{i}-0,64 \cdot W_{i}^{2}}{S_{1}^{0,63}} .
$$

Розрахунковими залежностями (3)-(6) можна користуватися для визначення зміни теплового потенціалу повітря в процесі сушіння букових пиломатеріалів. 3 іншого боку, ентальпія повітря визначається (описується) відомою залежністю, яку можна представити у зміненому вигляді як

$$
H_{i}=\left(t_{c}\right)_{i}+0,622 \cdot\left[1,93\left(t_{c}\right)_{i}+2490\right] \frac{\phi_{i} P_{H i}}{P_{a}-\phi_{i} P_{H i}} .
$$

Порівнявши ліву і праву сторони рівнянь (6) та (7), отримаємо загальне розрахункове рівняння

$$
\begin{gathered}
\frac{2880,75+23,75 \cdot W_{i}-0,64 \cdot W_{i}^{2}}{S_{1}^{0,63}}= \\
=\left(t_{c}\right)_{i}+0,622 \cdot\left[1,93\left(t_{c}\right)_{i}+2490\right] \frac{\phi_{i} P_{H i}}{P_{a}-\phi_{i} P_{H i}} .
\end{gathered}
$$

яке поєднує режимні параметри середовища $\left(t_{c}, \varphi\right)$ та характеристику матеріалу $\left(W, S_{1}\right)$ в процесі сушіння букових пиломатеріалів.

Тиск насичення сухої пари визначається за відомою формулою

$$
P_{H}=640,4 \cdot \exp \left(\frac{17,25 \cdot t_{c}}{238+t_{c}}\right), \text { Па. }
$$

Формула (9) є справедливою для діапазону температури середовища від 0 до $90{ }^{\circ} \mathrm{C}$.

Висновки. Основою для розроблення ресурсоощадної технології сушіння деревини є збереження ії̈ якісних показників, зменшення витрат матеріальних, енергетичних і трудових ресурсів. Одним із таких завдань $є$ визначення теплового потенціалу сушильного середовища, який створюється в сушильній камері для забезпечення проведення процесу сушіння за раціональними режимами. Отже, тут можна сформулювати такі висновки:

Розглянуто процес конвективного сушіння букових пиломатеріалів раціональними низькотемпературними режимами товщиною від 19 до 70 мм. Для аналізу деяких показників обрано букові пиломатеріали товщи- ною $S_{1}=40$ мм, як найбільш вживаного та середнього по товщині сортименту.

Величину ентальпії визначали для різних ступенів режиму. Наприклад, зміна ентальпії для пиломатеріалів товщиною $S_{1}=40$ мм (за режимами I. В. Кречетова) відбувалась так: від першого ступеня $(H=331,6$ кДж/кг) величина ентальпії зросла до $H=378,0$ кДж/кг (коли $W$ = 30-25\%), а наприкінці процесу сушіння зменшилася до $H=262,0$ кДж/кг.

Інтегральне значення ентальпії залежно від товщини змінилось від 28,95·10 3 кДж/кг для товщини пиломатеріалів $S_{1}=40$ мм до $12,0 \cdot 10^{3}$ кДж/кг для товщини $S_{1}=$ 70 мм. Аналогічною була зміна ентальпії для інших режимів. Наприклад, для режимів за редакцією П. В. Соколова інтегральне значення ентальпії зменшилося від $29,15 \cdot 10^{3}$ кДж/кг до $13,8 \cdot 10^{3}$ кДж/кг, а для режимів Brunner-Hildebrand - $\quad$ від $22,72 \cdot 10^{3}$ кДж/кг до $18,36 \cdot 10^{3}$ кДж/кг.

Зміну величини ентальпії середовища під час сушіння можна використати для створення алгоритму роботи агрегата теплової енергії сушильної камери, чим буде заощаджено значну кількість витрат теплової енергії.

\section{Перелік використаних джерел}

Auflage, S. (1987). Brunner-Hildebrand. Die Schnitholztrocknung: Buchdruckwerkstatten, Hannover. Gm.bH, Vep. Leipzig, 322 p.

Bilei, P. V. (2005). Teoretychni osnovy teplovoi obroblennia i sushinnia derevyny. Kolomiya: Vik, 364 p. [In Ukrainian].

Bilei, P. V., \& Pavliust, V. M. (2008). Sushinnia ta zakhyst derevyny. Lviv: Kolorove nebo, 312 p. [In Ukrainian].

Bilei, P. V., Petryshak, I. V., Sokolovskyi, I. A., \& Soroka, L. Ya. (2013). Teplomasoobminni protsesy derevoobrobky. Lviv: ZUKTs, 376 p. [In Ukrainian].

Krechetov, I. V. (1972). Sushka drevesiny. Moscow: Lesn. prom-st, 440 p. [In Russian].

Krechetov, I. V. (1987). Sushka i zashhita drevesiny. Moscow: Lesn. prom-st, 432 p. [In Russian].

Ozarkov, I. M., Soroka, L. Ya., \& Gryciuk, Yu. I. (1997). Fundamentals of aerodynamics and heat-mass exchange: manual. Kyiv: IZMN Publishing, $280 \mathrm{p}$.

Sokolov, P. V. (1968). Sushka drevesiny. Moscow: Lesn. prom-st, 360 p. [In Russian].

I. A. Sokolovskyi

Ukrainian National Forestry University, Lviv, Ukraine

\section{ENERGY CHARACTERISTICS OF DRYING MODES OF BEECH LUMBER}

The paper considers some essential scientific and applied aspects of the analysis of modes according to the thermal potential of the drying medium - the heat capacity of humid air. The authors present calculation formulas for determining the heat capacity and moisture content of air as a drying agent. To conduct our research we have chosen low-temperature drying modes for beech lumber edited by Prof. I.V. Krechetov, Prof. P.V. Sokolov, and also European enterprise Brunner-Hildebrand. We have analyzed drying modes according to the magnitude of air enthalpy change for different degrees of drying modes and different thicknesses of beech lumber (thickness ranges from $S_{1}=19 \mathrm{~mm}$ to $S_{1}=70 \mathrm{~mm}$ ). We provide the table summarizing the integral value of enthalpy for selected lumber modes and thickness. We applied the parabola equation of the third order to approximate the change in enthalpy of air depending on the wood moisture content. An integral form of the equation for changing the enthalpy of air depending on the moisture content of the wood is given. Approximation dependencies have an adequate approximation to the estimation ones, as can be seen from the graphs given in the work. We have also determined that for all the drying modes described in the work, the integral value of enthalpy decreases with increase of lumber thickness, which is confirmed by the fact that for the drying of larger thicknesses of lumber, the heat potential should be lower, due to lower heat expenditure for the drying process. We have revealed that a period of change in humidity from $W=40 \%$ to $W=20 \%$ requires the greatest expenditure of heat energy due to the highest moisture gradient in the thickness of the material. We have proved that it is necessary to regulate the operation of heat energy units in accordance with the expenditure of heat energy for the drying process.

Keywords: drying mode; lumber; wood moisture; heat capacity and moisture content of the drying medium; integral value of enthalpy; approximation. 